\title{
Waldo Aránguiz Thompson \\ (Santiago, 21 de octubre de 1926 - Santiago, 20 de mayo de 2017)
}

La escena coral chilena despide a un hombre que, con gran entrega y amor por la música vocal, se transformó en uno de los pilares en el que se cimenta la actividad coral chilena. Inició su vínculo con la música desde niño, cuando era miembro del coro del Instituto de Humanidades Luis Campino, dirigido por el maestro Mario Baeza Gajardo (1916-1998). Mientras estudiaba en el Seminario Pontificio, y luego en la Pontificia Universidad Católica de Chile, fue instruido en canto gregoriano y polifonía sacra por el presbítero Fernando Larraín Engelbach, maestro de capilla y organista. Posteriormente continuó su formación vocal en la Escuela Moderna de Música con Clara Oyuela Supervielle (19072001), y en armonía y contrapunto con Miguel Aguilar Ahumada.

Logró incorporarse como director asistente al Coro de la Universidad de Chile, dirigido por el mismo maestro Baeza, en 1950. Comenzó entonces a escribir arreglos y armonizaciones, incluyendo notables adaptaciones de música tradicional chilena, oficio que también desempeñó para otra agrupación del mismo director musical, el Coro de la Universidad Técnica del Estado. Su amplio manejo de repertorio y conocimiento de las problemáticas y características organológicas propias de esta conformación se dejan ver en su limpia escritura, impecable sentido melódico de las voces, uso consciente de la tesitura y registro, y asombrosa simpleza de lectura. El valor de estos trabajos se extiende hasta la escena actual, en que todavía gozan de merecida circulación.

Como director, mediante una incansable labor artística y de gestión, se transformó en uno de los principales impulsores del auge de la música coral vivido entre las décadas de 1960 y 1970 . Dirigió decenas de agrupaciones chilenas, entre ellas el coro de la Universidad Católica de Chile, y fundó también algunas de ellas, como el Coro del Puerto de San Antonio, que dirigió por 25 años. Una muy especial mención merece el Coro Filarmónico Municipal, que funcionó desde 1962 por catorce años en las temporadas sinfónico-corales y de ópera del Teatro Municipal de Santiago, y estaba conformado por un centenar de aficionados. A partir de 1975, esta agrupación comienza a llamarse Coro Ars Viva, que Aránguiz dirigió continuadamente y que subsiste hasta hoy. Participó en el estreno y grabación de obras emblemáticas de esos años, como el Oratorio para el pueblo (1965) de Ángel Parra y la Cantata de los Derechos Humanos Caín y Abel (1978) de Alejandro Guarello Finlay y el grupo Ortiga.

Una beca del Departamento de Estado de Estados Unidos y la Fundación Rockefeller hicieron posible que Aránguiz se perfeccionara entre 1966 y 1967 con el destacado director coral Robert Shaw (1916-1999) en la Meadow Brook School of Music de la Universidad de Oakland, California, oportunidad en que el maestro nacional pudo establecer relaciones con una auténtica red de directores de toda América. Esto lo fortaleció para desempeñar la intensa actividad gremial que lo caracterizó, iniciándola en 1957 como uno de los miembros fundadores de la Federación Nacional de Coros de Chile (FEDECOR), y en varias ocasiones siendo elegido como su presidente. Además, se desempeñó como vicepresidente de la Asociación Latinoamericana de Canto Coral (ALACC) en Brasil, entre 1996 y 1999, para luego ser elegido Presidente Internacional de la institución. A partir de 2002 fue vicepresidente del Consejo Chileno de la Música, y dos años más tarde es elegido presidente del Consejo Coral de Chile, organismo formado por todas las instituciones corales del país. En 2009 su experiencia y profundo conocimiento quedaron evidenciados ante una audiencia más masiva al participar como presidente del jurado del programa televisivo Todos a coro, transmitido por TVN.

"Pareciera que por fin Latinoamérica hubiera tomado conciencia de su común raíz y destino, y de la importancia de subrayar su identidad ante el resto del mundo", escribía enfáticamente el maestro Aránguiz en su escrito "Presencia coral de Chile en América Latina", publicado en la Revista Musical Chilena $^{1}$. Una somera revisión de su notable carrera, junto con los testimonios de tantos cantantes, profesionales o aficionados que fueron formados por él, permiten dar cuenta de su generoso aporte a esta toma de conciencia, y en la generación de una actividad coral que se mostró con dignidad ante el mundo. Con abnegado esfuerzo y profunda convicción, Waldo Aránguiz se transformó en uno

1 LIV/194 (julio, diciembre, 2000), pp. 95-98. 
de los principales articuladores del movimiento que ya había iniciado Mario Baeza, perpetuándolo hasta nuestros días. Solo es posible agradecer este regalo, esta semilla que ha germinado, y honrar su ejemplo emprendiendo los más serios esfuerzos para el cultivo de la actividad coral en nuestro país y en el continente.

Julio Garrido Letelier

Facultad de Artes. Universidad de Chile julio.garrido.l@uchile.cl

\section{Ariel Vicuña / Carlos de Bikunia / Selim Kartal (Valparaíso, 20 de septiembre de 1945 - Santiago, 20 de julio de 2017)}

Cada ser humano es único y diferente a los demás, aunque el sistema actual en el que vivimos se esmere en someternos y uniformarnos según moldes estandarizados. Consciente de ello, Ariel Vicuña, durante los casi 72 años que vivió en este mundo, supo ser él mismo, celoso de su libertad. Fue su opción, que la ejerció en forma innata, intransable.

Consecuentemente, si bien su nombre completo es Carlos Ariel Fortunato Vicuña Navarro, para marcar la diferencia y evitar cualquier confusión, acaso a modo lúdico, él buscaba alternativas y seudónimos. De hecho, cuando era más joven, durante un tiempo se hizo llamar Carlos de Bikunia y, más recientemente, Selim Kartal, respondiendo a su carácter religioso y autoral.

Ariel fue el mayor de una familia de 7 hermanos: 2 mujeres y 5 hombres. Se crió en un ambiente singular, amable y acogedor, rodeado de artistas y libros. Su padre, José Miguel Vicuña Lagarrigue, era poeta y escritor de ensayos históricos; su madre, Eliana Navarro Barahona, era poetisa. Ambos trabajaron en la Biblioteca del Congreso Nacional y, entre otras iniciativas, crearon la sección de "libros raros y valiosos", todavía existente. En su casa acostumbraban a tener tertulias con ilustres visitas, como Nicanor Parra (que a veces se quedaba a alojar por varios días), Humberto Díaz-Casanueva y Óscar Hahn, entre otros; o a compositores como Humberto Maturana y Gustavo Becerra. En este contexto, tempranamente descubrió su vocación de poeta y músico.

De niño se caracterizó por ser un gran lector e investigador en la biblioteca de su casa, buscador de sorpresas literarias. Así llegó a leer -todavía en su infancia- Las mil y una noches (versión de J. C. Mardrus), libro que lo marcó de por vida. Producto de ello se convirtió al islam y entre los diversos colegios en que estudió (Colegio Mariano, Liceo Alemán, Liceo de Hombres...) creó un movimiento anticatólico, que llamó el "destinismo", doctrina basada en la predestinación. Sus compañeros seguidores se denominaban "los vicuñistas" y muchas veces, a modo de protesta, hacían huelgas y se resistían a entrar a clases. Todo esto -desconcertante para el orden establecido- finalmente generó que Ariel terminara sus estudios secundarios mediante exámenes libres. De esta manera, su vocación libertaria quedó manifiesta desde su juventud.

En relación con su desarrollo artístico, la poesía la aprendió en su entorno familiar, seguramente con cierta herencia genética y contagio ambiental, junto con su talento personal. Ya a los 11 años escribía poemas y en su vida llegó a publicar 6 libros (además de 2 inéditos que su familia espera publicar, dentro una compilación completa de su obra literaria). En el ámbito musical estudió piano, clarinete y oboe; también conoció el violín aunque no lo tocaba. Las clases de composición las tuvo con Sergio Ortega en la Escuela Vespertina de la Universidad de Chile, entre 1969 y 1970, y el desarrollo de su lenguaje musical finalmente lo llevó a explorar en el dodecafonismo. De hecho, en el último tiempo investigaba nuevos caminos para trabajar las series dodecafónicas, dividiéndolas en 2 "subseries de 6 notas", complementarias, generando en ellas diferentes formas de interacción. Incluso estaba empeñado en escribir un tratado acerca de su método, incluyendo temas como "disolución de la tonalidad", "principios armónicos atonales" y "saturación armónica”, con el título general de "Música atonal de principio dual". 